\title{
Blocking polar body with cytochalasin B in the fertilized eggs of the small abalone, Haliotis diversicolor supertexta (Lischke), and the development and ploidy of the resultant embryos
}

\author{
H-S Yang ${ }^{1,2}$, Y-Y Ting ${ }^{2}$ \& H-C Chen ${ }^{1}$ \\ ${ }^{1}$ Department of Zoology, National Taiwan University, Taipei, Taiwan, ROC \\ ${ }^{2}$ Tainan Fish Culture Station of the Taiwan Fisheries Research Institute, Keelung, Taiwan, ROC
}

Correspondence: Hong-Shii Yang, \#4, Hai-Phu, San-Ku, Chi-Ku, Tainan, Taiwan, ROC

\begin{abstract}
The effects of blocking polar body I (PB1) or polar body II (PB2) with four different dosages of cytochalasin B (CB) on the development and ploidy of resultant embryos were studied in the small abalone, Haliotis diversicolor supertexta (Lischke). To block the release of PB1, the fertilized eggs were treated with $0.25,0.5,1.0$ or $2.0 \mathrm{mg} \mathrm{L}^{-1}$ of $\mathrm{CB}$ for $10 \mathrm{~min}$ beginning at $3 \mathrm{~min}$ post-fertilization at $24^{\circ} \mathrm{C}$. To block the release of $\mathrm{PB} 2$, the fertilized eggs were treated under the same conditions as PB1, except that the treatment was begun $10 \mathrm{~min}$ post-fertilization. In the control group, only $41.8 \%$ of the cells had a diploid number of 32 chromosomes, although spontaneous haploids $(9.0 \%)$, tripolids $(7.5 \%)$ and aneuploids $(41.7 \%)$ were also observed. In CB treatment of PB1 and PB2 groups, $5.0-28.6 \%$ of the cells remained as diploid, triploids (10.0-18.9\%) and aneuploids (41.1$61.0 \%$ ). With regard to the development of the resultant embryos, the proportion of normal embryos in the control group was $87 \%$, while in the treatment groups, the proportions of normal embryos in the PB1 and PB2 groups were $57-58 \%$ and $53-56 \%$ in the $0.25 \mathrm{mg} \mathrm{L}^{-1}$ and $0.5 \mathrm{mg} \mathrm{L}^{-1} \mathrm{CB}$ treatments, respectively. From this data on induced triploids and the resultant development of normal embryos, the proportions suggest that 0.25 $0.5 \mathrm{mg} \mathrm{L}^{-1}$ of $\mathrm{CB}$ for $10 \mathrm{~min}$ was sufficient for
\end{abstract}

blocking the release of $\mathrm{PB} 1$ or $\mathrm{PB} 2$ to produce triploids in the small abalone.

\section{Introduction}

The potential of the chromosome manipulation technique with clouding temperature (Quillet \& Panelay 1986; Fujino, Okumura \& Inayoshi 1987). pressure (Chaiton \& Allen 1985; Arai, Naito \& Fujino 1986) and chemical treatments (Stanley, Allen \& Hidu 1981; Tabarini 1984; Beaumont \& Contaris 1988) to induce triploidy or tetraploidy in organisms has previously been discussed. In most vertebrates, eggs mature after completion of meiosis I, but in many marine mollusks, mature eggs are arrested at prophase I of meiosis I (Ahmed 1973; Lu 1986; Strathmann 1987). These eggs only complete meiosis I (i.e. release polar body I, PB1) and meiosis II (i.e. release polar body II, PB2) after fertilization or activation. The interruption of meiosis in eggs provides a unique opportunity for the manipulation of PB1 or PB2 triploids. Triploids are organisms with three sets of chromosomes in each cell which can theoretically cause sterility because homologous chromosomes cannot synapse in meiosis. This has been well established in some species of fish (Benfey, Sutterlin \& Thompson 1984; Chourrout 1984) and molluscs (Longo 1972; Beaumont \& Fairbrother 1991). Stanley etal. (1981) used cytochalasin B (CB) during PB1, which resulted in triploid and tetraploid embryos in the American oyster, Crassostrea virginica (Gmelin). Similarly, both 
triploid and tetraploid embryos were produced by blocking PB1 in the blue mussel, Mytilus edulis (Lamarck), (Yamamoto, Sugawara \& Oshino 1988) and Pacific abalone, Haliotis discus hannai (Ino) (Arai etal. 1986). Stephens (1989) reported that CB blocking of PB1 in the Pacific oyster, Crassostrea gigas (Thunberg), produced tetraploids, not triploids. Guo, Cooper, Hershberger \& Chew (1992) reported that $\mathrm{CB}$ acting on the $\mathrm{PB} 1$ of the Pacific oyster resulted in diploids, triploids, tetraploids and a majority of aneuploids in embryos. This metabolite of a fungus prevents cytokinesis, but not chromosome replication (Copeland 1974). Cytochalasin B is widely used in the production of $\mathrm{PB} 2$ triploids in the Pacific oyster, and it is an important part of the oyster culture industry in USA and Canada because of the sterility of these animals (Chew 1984; Allen, Downing \& Chew 1989). Stanley, Hidu \& Allen (1984) found that PB1 triploids may grow better than PB2 triploids; however, the larval survival rate of the former may be below that of the latter. However, the available data are still inconclusive. The variation in the production of triploids may be caused by differences in experimental methods and conditions.

It is still unknown what the optimum amounts of CB should be for blocking PB1 or PB2 in the small abalone, Haliotis diversicolor supertexta (Lischke). The small abalone is currently raised in commercial hatcheries in Taiwan (Chen \& Yang 1979; Chen 1984). Triploid abalone will be come an important part of the abalone culture industry if it has a sufficiently fast growth rate. However, available data provide insufficient information on the question of what the dosage of $\mathrm{CB}$ should be to block PB1 or PB2. In the present study, karyological analyses were used to determine ploidy in embryos, and the authors report their initial trials in adjusting dosages of $\mathrm{CB}$ treatment on $\mathrm{PB} 1$ or $\mathrm{PB} 2$ in the small abalone. It was anticipated that results of the present study would help to clarify the optimum conditions for inducing triploids in the small abalone.

\section{Materials and methods}

\section{Gamete preparation}

Gametes were obtained by artificially induced spawning of sexually mature parent abalone using thermal variation. The abalone were separated into male and female groups, and each group was placed in a 24-L plastic container filled with $10 \mathrm{~L} \mathrm{UV-}$ irradiated sea water. Spawning was induced by changing the water temperature back and forth between 23 and $28^{\circ} \mathrm{C}$ during a 5 -h cycle. Water temperature was increased with a heater and decreased with water at $4{ }^{\circ} \mathrm{C}$. Two to three cycles were sufficient for inducing male and female spawning. The water temperature for obtaining gametes was maintained at $\approx 24 \pm 1{ }^{\circ} \mathrm{C}$ during spawning and fertilization.

\section{Cytochalasin B treatment}

In the cytochalasin $\mathrm{B}$ treatment, $1.0 \mathrm{mg}$ of $\mathrm{CB}$ (Sigma), dissolved in $1.0 \mathrm{~mL}$ dimethyl sulphoxide (DMSO) as a stock solution, was added to $2 \mathrm{~L}$ of egg suspension $\left(10^{4}\right)$, and then the dosages were adjusted to $0.25,0.5,1.0$, and $2.0 \mathrm{mg} \mathrm{L}^{-1}$, respectively. To block the release of PB1, the fertilized eggs were treated with four dosages for $10 \mathrm{~min}$ beginning at $3 \mathrm{~min}$ post-fertilization under $24^{\circ} \mathrm{C}$ sea water. To block the release of $\mathrm{PB} 2$, the fertilized eggs were treated under the same conditions as PB1, except that the treatment was begun at $10 \mathrm{~min}$ postfertilization. The CB was removed by collection and the rinsing of treated eggs on a $60-\mu \mathrm{m}$ screen. The eggs were then returned to $0.1 \%$ DMSO in sea water for $30 \mathrm{~min}$ to remove any residual $\mathrm{CB}$. In the control group, the fertilized eggs were only treated with $0.1 \%$ DMSO. The embryos were stocked at a density of 5 embryos $\mathrm{mL}^{-1}$.

\section{Determination of the development and ploidy of embryos}

Samples of embryos $\left(n=10^{3}\right)$ were collected $6 \mathrm{~h}$ after fertilization and fixed in 5\% formalin for the calculation of the proportion of normal morphology embryos. The ploidy of the resultant embryos in both the control and treated groups was determined by karyological analysis. Samples for karyological analysis were taken at $6 \mathrm{~h}$ post-fertilization. Embryos were first treated with $0.01 \%$ colchicine for $30 \mathrm{~min}$. After the colchicine was removed, nine parts of a hypotonic solution $(0.075 \mathrm{M} \mathrm{KCl})$ was added to one part embryo suspension for $30 \mathrm{~min}$. The hypotonic solution was then removed, and the samples were fixed in a solution of one part glacial acetic acid and three parts absolute methanol ( $/ \mathrm{v}$ ) for $1 \mathrm{~h}$. This solution was replaced with fresh fixing solution for an additional $1 \mathrm{~h}$. Then the fixing solution was removed and the samples were stored 
in methanol at $4^{\circ} \mathrm{C}$. The samples were placed in a 1:1 glacial acid and absolute methanol solution before staining. The cell suspensions were dropped onto $45-50^{\circ} \mathrm{C}$ slides and air dried overnight. Slides were stained with $5 \%$ Giemsa in $\mathrm{pH} 6.5$ phosphate buffer for $30 \mathrm{~min}$ and sealed with Canada balsam. These were then scanned under a compound microscope for chromosome determination. In the present study, ploidies were classified as follows: (15-19) haploid; (30-34) diploid; (45-49) triploid; (60-64) tetraploid; and (80-84) pentaploid. All other ploidies were considered to be aneuploid.

\section{Data analysis}

Differences between the control and treatment groups in the proportion of normal morphology and the ploidies of embryos were tested with an analysis of variance (ANOVA).

\section{Results}

\section{Time of release of two polar bodies and first mitosis}

In the control groups, PB1 was released around $8 \pm 1 \mathrm{~min}$ post-fertilization, PB2 was released around $19 \pm 1$ min post-fertilization and first mitosis occurred at $43 \pm 1 \mathrm{~min}$ post-fertilization at $24^{\circ} \mathrm{C}$. In the CB-treated PB1 groups, PB1 was not observed in most of the eggs at the time expected $(8 \pm 1 \mathrm{~min})$. In the CB-treated PB2 groups, PB2 was not observed in most of the eggs at the time expected $(19 \pm 1 \mathrm{~min})$. The first mitosis occurred at about $50-60$ min postfertilization in the CB-treated PB1 and PB2 groups. The early mitosis in the treated groups appeared to be normal, but apparently less synchronized than that in the control groups.

\section{Proportion of normal morphology of resultant embryos}

In the control group, $98 \%$ of all eggs developed to the gastrula stage at $6 \mathrm{~h}$ post-fertilization, and $2 \%$ did not because of a lack of fertilization. The normal embryos were counted in both the control and treated groups. In the control group, the normal embryo proportion was $87 \%$, while in the PB1 blocking treatment groups only $57 \%, 53 \%, 36 \%$ and $15 \%$ from eggs subjected to $\mathrm{CB}$ at doses 0.25 . $0.5,1.0$ and $2.0 \mathrm{mg} \mathrm{L}^{-1}$, respectively, were normal. In the PB2 blocking treatment, only 58\%, 56\%,
$39 \%$ and $6 \%$ of the embryos from eggs subjected to $\mathrm{CB}$ at doses $0.25,0.5,1.0$ and $2.0 \mathrm{mg} \mathrm{L}^{-1}$. respectively, were normal. There were significant differences between the 0.25 and $0.5 \mathrm{mg} \mathrm{L}^{-1} \mathrm{CB}$ treatment groups $(P<0.05)$, the 1.0 and $2.0 \mathrm{mg} \mathrm{L}^{-1}$ CB-treatment groups $(P<0.001)$, and the control, but there was no significant difference $(P>0.05)$ between the $\mathrm{PB} 1$ and $\mathrm{PB} 2 \mathrm{CB}$-treatments for the same dosage level of $\mathrm{CB}$ (Fig. 1). In the CB treatment and control groups, all embryos developed to swimming trochophores at $9 \mathrm{~h}$ post-fertilization, and the number of swimmers hatched was high in both the treatment and control groups. Observation of the swimming ability of the trochophores showed that the trochophores in the $\mathrm{CB}$-treatment groups were less active than those in the control group, and a higher dosage of $\mathrm{CB}$ was directly proportional to a decrease in the activity of swimming. The abnormal trochophores were either deformed or constantly swam in a circular motion on the bottom of the beaker. In the groups with dosages of 0.25 and $0.5 \mathrm{mg} \mathrm{L}^{-1}$, and in the control group, the larvae of trochophores developed to veligers by $20 \mathrm{~h}$ postfertilization, but in the groups with dosages of 1.0 and $2.0 \mathrm{mg} \mathrm{L}^{-1}$, the swimming trochophores gradually died before any metamorphosis into veligers. The mitotic index of the CB-treated groups was noticeably lower than in control groups.

\section{Proportion of ploidy of resultant embryos}

In the control group, the karyological analysis revealed that $41.8 \%$ of all cells examined had a diploid number $(2 \mathrm{n}=32)$ of chromosomes. Only $9.0 \%$ and $7.5 \%$ could be classified as haploids and tripolids, and about half $(41.7 \%)$ of cells were classified as aneuploids. No tetraploids or pentaploids were found in the control group (Table 1).

Compared with the control group, all of the CBtreatment groups had increases in the proportion of polyploid and aneuploid cells, and decreases in the proportion of diploid cells (Table 1). Comparing the classified triploids of the treatment groups, an increase in the dosage of $\mathrm{CB}\left(1.0\right.$ and $\left.2.0 \mathrm{mg} \mathrm{L}^{-1}\right)$ could not induce a higher proportion of triploids; in contrast, the proportion of aneuploids increased. Comparing the triploid proportions of the PB1 and PB2 groups, the present authors found no significant differences $(P>0.05)$ for the same level dosage of $\mathrm{CB}$. The majority of the cells were either diploids $(10.8 \%)$, triploids $(18.9 \%)$, tetraploids $(5.4 \%)$ or aneuploids $(51.4 \%)$ in the $0.25 \mathrm{mg} \mathrm{L}^{-1} \mathrm{~PB} 1$ group 


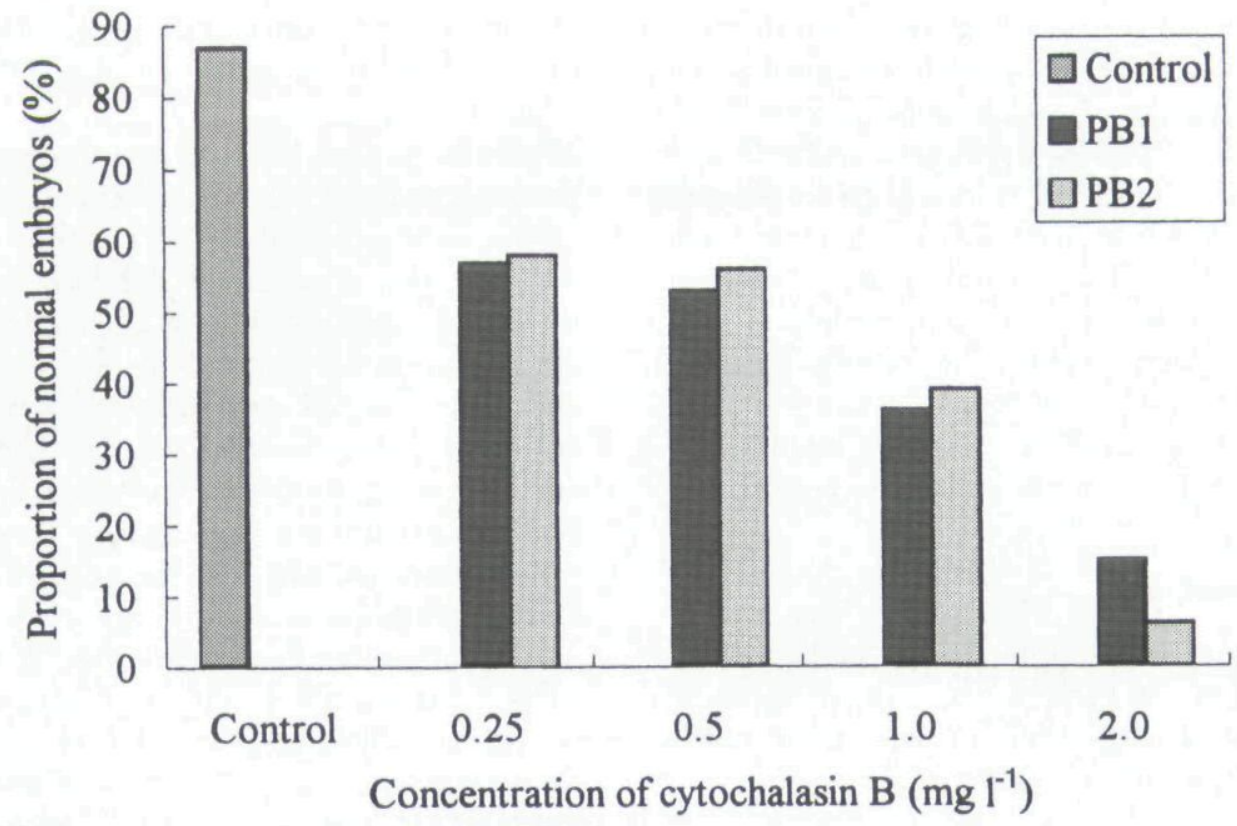

Figure 1 The proportion of 6-h-old normal embryos counted after normal fertilization (control), and blocking of the first polar body (PB1) and second polar body (PB2) in the fertilized eggs of the small abalone with four different dosages of cytochalasin B (CB).

Table 1 The proportion of ploidy in the cells of 6-h-old embryos after normal fertilization (control), and blocking of the first polar body (PB1) and the second polar body (PB2) in the fertilized eggs of the small abalone with four different doses of cytochalasin B (CB): (1n) haploid: (2n) diploid; (3n) triploid; (4n) tetraploid; (5n) pentaploid; and (An) aneuploid. Treatment groups were compared with the control by ANOVA.

\begin{tabular}{|c|c|c|c|c|c|c|c|c|c|}
\hline \multirow[b]{2}{*}{$\begin{array}{l}\text { Dosage of } \mathrm{CB} \\
\text { treatment }\left(\mathrm{mg} \mathrm{L}^{-1}\right)\end{array}$} & \multirow[b]{2}{*}{ Polar body } & \multirow[b]{2}{*}{$\begin{array}{l}\text { Proportion of } \\
\text { normal embryos }\end{array}$} & \multicolumn{6}{|c|}{ Proportion of ploidy } & \multirow[b]{2}{*}{ An } \\
\hline & & & Sample size & $1 n$ & $2 n$ & $3 n$ & $4 n$ & $5 n$ & \\
\hline Control & & 87 & 67 & 9.0 & 41.8 & 7.5 & 0 & 0 & 41.7 \\
\hline \multirow[t]{2}{*}{0.25} & PB1 & $57^{*}$ & 37 & 8.1 & $10.8^{*}$ & $18.9^{*}$ & 5.4 & 5.4 & 51.4 \\
\hline & PB2 & $58^{*}$ & 39 & 7.7 & $15.4^{*}$ & $17.9^{*}$ & 0 & 0 & $59.0^{*}$ \\
\hline \multirow[t]{2}{*}{0.5} & PB1 & $53^{*}$ & 47 & $10.6^{\star}$ & $6.4^{*}$ & $12.8^{\star}$ & 4.3 & 12.8 & 53.1 \\
\hline & PB2 & $56^{*}$ & 45 & $11.1^{*}$ & 26.7 & $17.8^{*}$ & 6.7 & 2.2 & 35.5 \\
\hline \multirow[t]{2}{*}{1.0} & PB1 & $36^{* *}$ & 18 & 5.6 & $16.7^{\star}$ & 11.1 & 5.6 & 0 & 61.0 \\
\hline & PB2 & $39^{* *}$ & 21 & 4.8 & 28.6 & $14.3^{*}$ & 0 & 0 & 52.3 \\
\hline \multirow[t]{2}{*}{2.0} & PB1 & $15^{\star *}$ & 19 & 5.0 & $5.0^{* \star}$ & 10.0 & 15.0 & 5.0 & $60.0^{*}$ \\
\hline & PB2 & $6^{\star \star}$ & 39 & $20.5^{\star}$ & $23.0^{*}$ & $15.4^{\star}$ & 0 & 0 & 41.1 \\
\hline
\end{tabular}

${ }^{*} P<0.05$.

${ }^{* *} \mathrm{P}<0.001$

(Fig. 2). However, a high proportion of cells examined in the CB-treated and control groups were classified as aneuploids (Table 1). A low proportion of haploids and pentaploids were also recorded in the CB-treated groups. In the present study, the frequency of chromosome numbers in the 

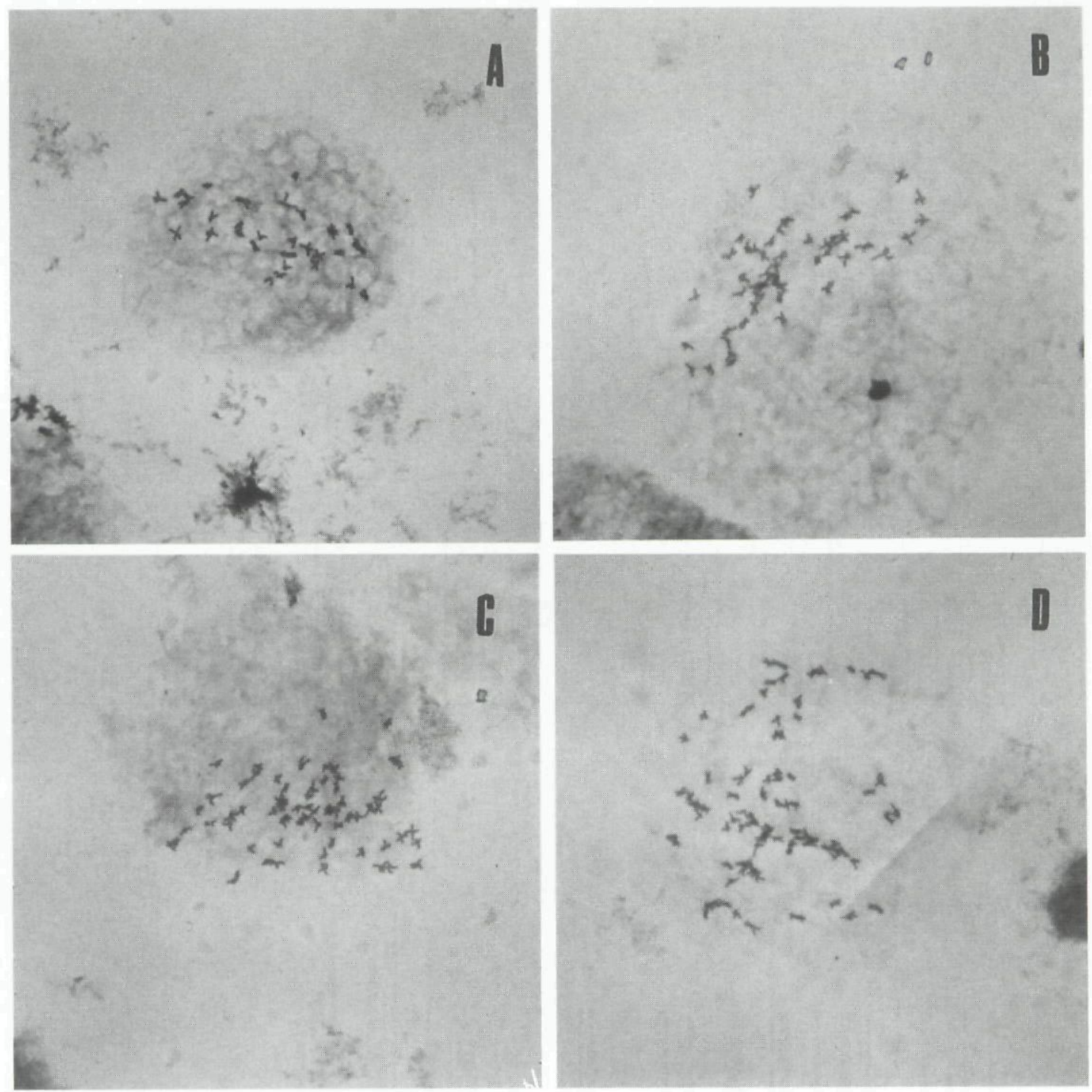

Figure 2 The metaphases of (a) diploid, (b) triploid, (c) tetraploid and (d) aneuploid cells produced by blocking the first polar body in the fertilized eggs of the small abalone with cytochalasin B.

control and CB-treatment groups showed a random distribution which indexed no relationship between the four dosages of $\mathrm{CB}$ and between two polar bodies (Fig. 3).

\section{Discussion}

The present study describes the results of the proportion of normal morphology and ploidy in 6-h-old embryos treated with CB in fertilized eggs of the small abalone. Factors such as temperature, salinity, timing and duration of treatment, and egg and sperm quality may affect the results of polyploidy and the survival of larvae. Lu (1986) demonstrated that different temperatures give different yields of triploids in the Pacific oyster. Stanley etal. (1981) revealed different proportions of polyploidy with different concentrations of $\mathrm{CB}$ in the American oyster. Tabarini (1984) reported only $66 \%$ and $94 \%$ triploidy of scallops, Argopecten irradians (Lamarck), in the 0.05 and $0.1 \mathrm{mg} \mathrm{L}^{-1}$ CB-treatments, respectively. In the above study, there was a relationship between triploidy and CB concentration. However, Tabarini (1984) did not discuss survival ratios at different $\mathrm{CB}$ concentrations. There is a question 
(a)

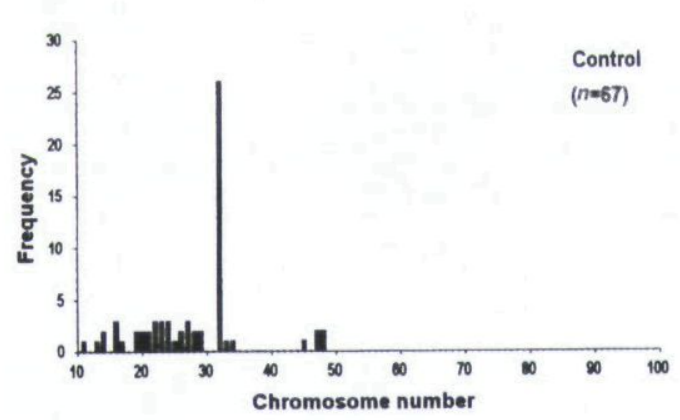

(c)

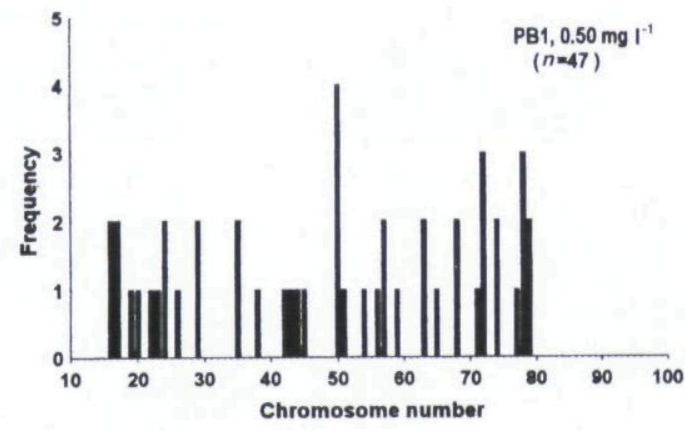

(e)

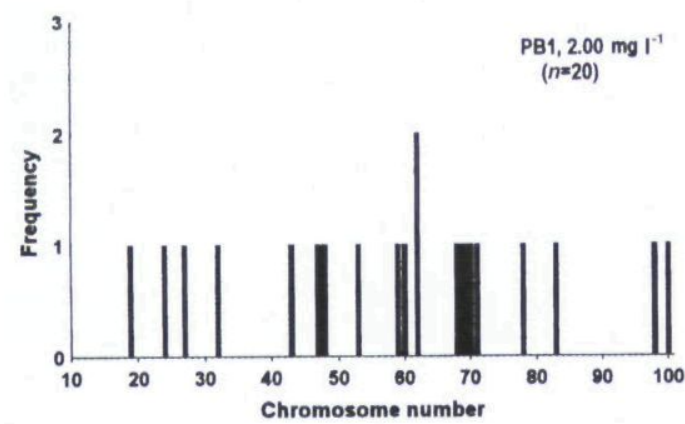

(g)

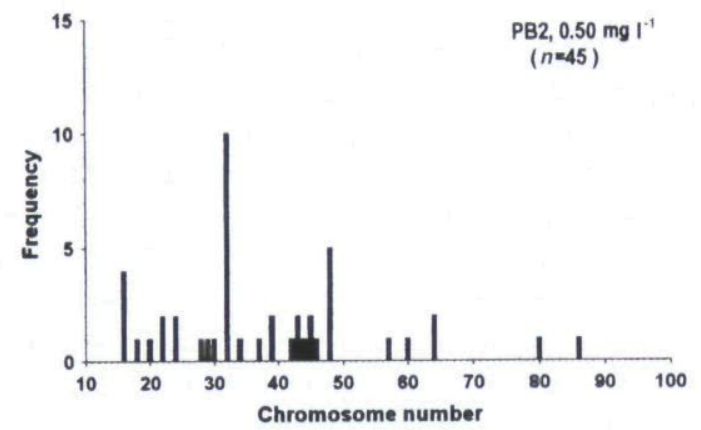

(b)

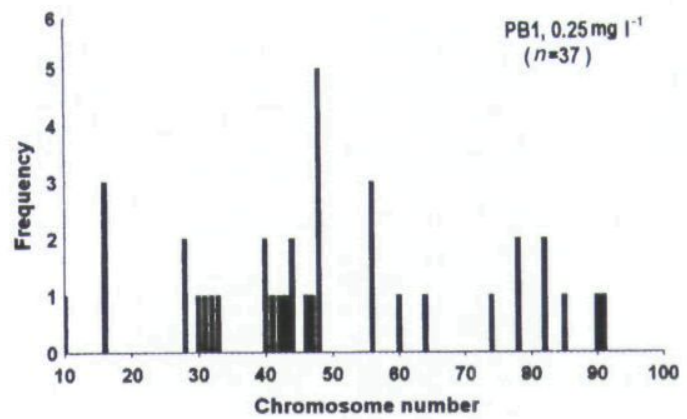

(d)

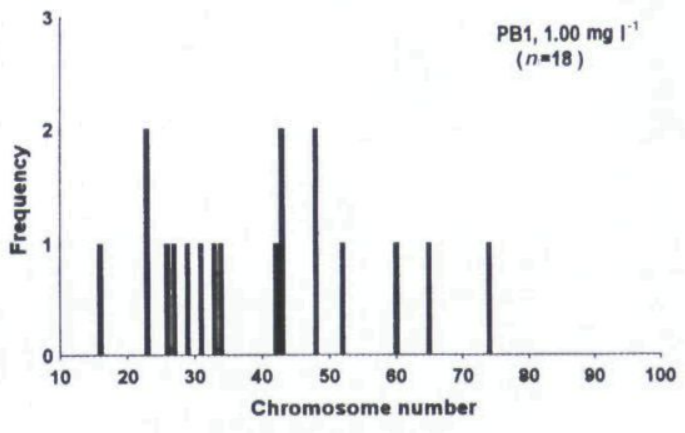

(f)

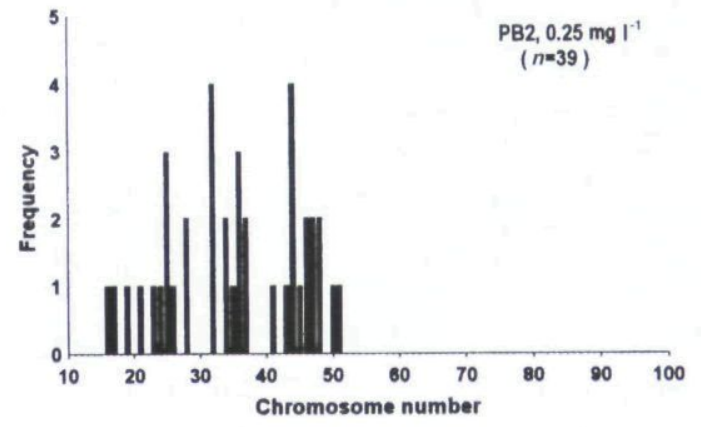

(h)

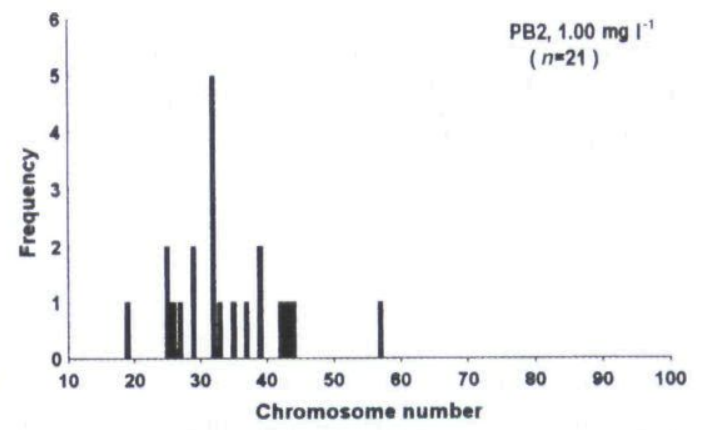


(i)

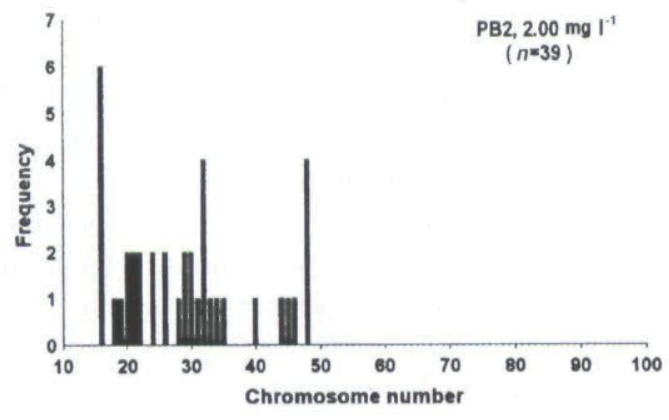

concerning the relationship between triploidy survival and the concentration of CB. High triploidy and survival rates must be considered in aquaculture. If a high proportion of triploidy was induced by a high dose of $\mathrm{CB}$, but this caused mass mortality of embryos, the data would be of no value for aquaculture. Conversely, a high survival rate with only a low proportion of triploidy would also be useless. It is necessary to find suitable parameters and to clarify optimum conditions for small abalone in aquaculture.

Cytochalasin is an effective method of inducting polyploids in a variety of animals. Cytochalasin B yields a higher survival rate than heat or pressure (Downing \& Allen 1987), but it is toxic to animal cells at high concentrations. A moderate dosage of $\mathrm{CB}$ has been successfully used to inducing triploidy. In the present study. the ratio of abnormal embryos was small in the control group. It is unlikely that these abnormal embryos were caused by DMSO, which is widely used with cultured cells and embryos. In the CBtreatment groups, a higher ratio of abnormality was caused by the $\mathrm{CB}$, and the results show that 1.0 and $2.0 \mathrm{mg} \mathrm{L}^{-1}$ of $\mathrm{CB}$ are toxic to the cells of small abalone. Allen etal. (1989) reported that $1.0 \mathrm{mg} \mathrm{L}^{-1}$ was used when inducing industrial triploids of the Pacific oyster. Stanley et al. (1981) demonstrated that triploids of the American oyster were induced at doses of $0.1-1.0 \mathrm{mg} \mathrm{L}^{-1}$ CB. In the bay scallop, triploids were induced at doses of $0.05-0.1 \mathrm{mg} \mathrm{L}^{-1} \mathrm{CB}$ (Tabarini 1984). In this study, the present authors found that some embryos were normal at doses of $1.0-2.0 \mathrm{mg} \mathrm{L}^{-1}$ CB; however, when embryos developed into hatched swimming trochophores, all the swimmers were abnormal. This showed that the small abalone was more sensitive to $\mathrm{CB}$ than the
Figure 3 The chromosome counts in embryos after (a) normal fertilization (control), and (b-e) blocking of the first polar body (PB1) and ( $\mathrm{f}-\mathrm{i})$ the second polar body (PB2) in the fertilized eggs of the small abalone with four different dosages of cytochalasin $\mathrm{B}(\mathrm{CB})$.

Pacific and American oysters, but less so than the scallop.

Duration of treatment is also an important parameter. In this experiment, the present authors could not explain the relationship between the difference in duration and survival and ploidy. However, the interval between the release time of PB1 (8 min), PB2 (19 min) and first mitosis (43 min) revealed that a duration of $10 \mathrm{~min}$ of $\mathrm{CB}$-treatment was a suitable parameter for blocking the release of the polar body. Although the 1.0 and $2.0 \mathrm{mg} \mathrm{L}^{-1} \mathrm{CB}$ groups had a low proportion of normal embryos, there may be a high normal rate if the duration time of CB-treatment is decreased. In the present study, the percentages of normal embryos in the $\mathrm{PB} 1$ and $\mathrm{PB} 2$ groups at the same dose of $\mathrm{CB}$ were not significantly different. This result conflicted with that obtained in the Pacific oyster, in which blocking PB1 always resulted in a higher mortality than blocking PB2 (Guo et al. 1992).

The control group in the present study had a diploid chromosome frequency number of 32 , in which there was a high ratio of aneuploids. It is unlikely that aneuploidy in the control group was caused by DMSO, which is widely used with cultured cells and embryos, and has no known effects on chromosome segregation. Since karyological techniques tend to create chromosome losses and overestimate the occurrence of aneuploidy, a low rate may be considered as an upper limit of aneuploidy in the chromosome preparation. Where $41.7 \%$ aneuploids were produced, the results were not only caused by the artifacts, but also by spontaneous chromosome segregation when the diploid chromosome number was not equal to $2 \mathrm{n}=32$. Gaffney, Scott, Koehn \& Diehl (1990) suggested that heterozygosity deficiency could be caused by the occurrence of aneuploids. The formation of aneuploidy 
gametes in molluscs may be common, particularly under environmental stress (Dixon 1982). It was the present authors' experience with the artificial propagation of small abalone that about half of the floating larvae did not survive during the settling stage. Haploids may result from specific failure of the sperm. It is difficult to explain the phenomenon of triploidy in the control group based on the present experimental design. Spontaneous triploids have been reported in amphibians, fish and molluscs and are probably caused by the fertilization of unreduced ova by normal sperm (Fankhauser 1945; Thorgaard \& Gall 1979; Guo et al. 1992).

On comparing the classified diploids of the CBtreated groups and the control group, it appears that the CB had acted on the cells during meiosis. In the present study, a high proportion of triploidy appeared in the 0.25 and $0.5 \mathrm{mg} \mathrm{L}^{-1} \mathrm{CB}$ groups, and a high dosage $\left(1.0\right.$ and $\left.2.0 \mathrm{mg} \mathrm{L}^{-1}\right)$ of $\mathrm{CB}$ did not enhance the formation of triploidy, but increased the incidence of aneuploidy. It was surprising that the tetraploids and pentaploids were not observed in any of the PB2 groups of the CB-treatment except the $0.5 \mathrm{mg} \mathrm{L}^{-1}$ group. The present authors cannot explain this phenomenon.

The detection of triploidy after blocking PB1 (18.9\%) and PB2 (17.9\%) in $0.25 \mathrm{mg} \mathrm{L}^{-1}$ of $\mathrm{CB}$ agrees with results from the Pacific oyster (15.6\%), but the incidence of tetraploids in the present study was only $5.4 \%$ in PB1 blocked groups, as compared with $19.4 \%$ reported by Guo etal. (1992). The present results also differ from other studies in which only triploid embryos (Quillet \& Panelay 1986) or tetraploid embryos (Stephens 1989) were observed after blocking PB1. This variation may be a result of differences in experimental methods, conditions and animal species.

The production of a large proportion of aneuploids by blocking PB1 and PB2 was unexpected. Aneuploids were commonly assumed to be the result of artifacts and CB-treatment. Guo, Hershberger, Cooper \& Chew (1992) explained that the formation of aneuploidy was caused by the randomized tripolarity and unmixed tripolarity of chromosome segregation, an effect of CB-treatment. Longo, Mathews \& Hedgecock (1993) also found that chromosomes formed a tripolar spindle during meiosis I after CB-treatment. As Guo et al. (1992) reported, chromosome tripolar segregation in moulds may explain the aneuploidy results owing to an unequal dyad of chromatids being lost in meiosis. In this study, CB caused chromosomes to be retained in the cell, resulting in a variety of ploidies that could be explained by a different type of chromosome segregation. In the present study, the frequency of chromosome number in the control and CB-treatment groups showed a random distribution that indexed no relationship between the four dosages of CB and the two polar bodies, demonstrating that the subsequent chromosome segregation in the cell to euploidy and aneuploidy is random. The randomness of chromosome segregation may explain this question. With regard to aneuploidy, there was a greater opportunity for the formation of aneuploids than other euploids because of the CBtreatment. The results conflict with studies in the Pacific oyster, where aneupoids of chromosome number fell into two groups in peaks between diploidy and triploidy, triploidy and tetraploidy (Guo etal. 1992). This difference in chromosome number distribution may a result of species differences.

The proportion of normal embryos and triploids in different dosages of $\mathrm{CB}$ demonstrated that results may improve if dosages of $\mathrm{CB}$ are maintained below $0.25 \mathrm{mg} \mathrm{L}^{-1}$, and the production of a large proportion of aneuploids in the control and CB-treatments suggests that the subsequent chromosome segregation is complicated.

\section{Acknowledgments}

This research was partially supported by the National Science Council, Republic of China, and the authors are also grateful to Dr I-Chiu Liao for supporting this research.

\section{References}

Ahmed M. (1973) Cytogenetics of oysters, Crassostrea gigas (Thunberg). Cytologia 38, 337-347.

Allen S.K., Downing S.L. \& Chew K.K. (1989) Triploid oysters, Crassostrea gigas (Thumberg); hatchery manual for producing. Washington Sea Grant Program, University of Washington Press Seattle, WA, 27 pp.

Arai K.F.. Naito F. \& Fujino K. (1986) Triploidization of the Pacific abalone, Haliotis discus hannai (Ino), with temperature and pressure treatments. Bulletin of the Japanese Society of Scientific Fisheries 52, 417-422.

Beaumont A.R. \& Contaris M.H. (1988) Production of triploid embryos of Tapes semidecussatus by the use of cytochalasin B. Aquaculture 73, 37-42.

Beaumont A.R. \& Fairbrother J.E. (1991) Ploidy manipulation in molluscan shellfish a review. Journal of Shellfish Research 10, 1-18. 
Benfey T.J., Sutterlin A.M. \& Thompson R.J. (1984) Use of erythrocyte measurements to identify triploid salmonids, Salmo salar. Canadian Journal of Fisheries and Aquatic Sciences 41, 980-984.

Chaiton J.A. \& Allen S.K. (1985) Early detection of triploidy in the larvae of Pacific oysters, Crassostrea gigas T., by flow cytometry. Aquaculture 48, 35-43.

Chen H.C. (1984) Recent innovations in cultivation of edible mollusks in Taiwan, with special reference to the small abalone Haliotis diversicolor and the hard clam Meretrix lusoria. Aquaculture 39, 1-11.

Chen H.C. \& Yang H.S. (1979) Artificial propagation of the abalone, Haliotis diversicolor supertexta L. China Fisheries Monthly 314, 1-3.

Chew K.K. (1984) Recent advances in the cultivation of mollusks in the Pacific United States and Canada. Aquaculture 39, 69-81.

Chourrout D. (1984) Pressure induced retention of second polar body and suppression of first cleavage in rainbow trout, Salmo gairdneri: production of all-triploids, alltetraploids, and heterozygous and homozygous diploid gynogenetics. Aquaculture 36, 111-126.

Copeland M. (1974) The cellular response to cytochalasin B: a critical overview. Cytologia 39, 709-727.

Dixon D.R. (1982) Aneuploidy in mussel embryos, Mytilus edulis L., originating from a polluted dock. Marine Biological Letters 3, 155-161.

Downing S.L. \& Allen S.K. (1987) Induced triploidy in the Pacific oyster, Crassostrea gigas T., Optimal treatments with cytochalasin B depend on temperature. Aquaculture 61, 1-15.

Fankhauser G. (1945) The effects of chromosome number on amphibian development. Quarterly Review of Biology 20, 20-78.

Fujino K., Okumura S.I. \& Inayoshi H. (1987) Temperature tolerance differences among normal diploid and triploid Pacific abalone, Haliotis discus hannai Ino. Nippon Suisan Gakkaishi 53, 15-21.

Gaffney P.M., Scott T.M., Koehn R.K. \& Diehl W.J. (1990) Interrelationships of heterozygosity, growth rate and heterozygote deficiencies in the coot clam, Mulinia lateralis Genetics 124, 687-699.

Guo X., Cooper K., Hershberger W.K. \& Chew K.K. (1992) Genetic consequences of blocking polar body I with cytochalasin B in fertilized eggs of the Pacific oyster, Crassostrea gigas T.: 1. Ploidy of resultant embryos. Biological Bulletin 183, 381-386.
Guo X., Hershberger W.K., Cooper K. \& Chew K.K. (1992) Genetic consequences of blocking polar body I with cytochalasin B in fertilized eggs of the Pacific oyster, Crassostrea gigas T.: II. Segregation of chromosomes. Biological Bulletin 183, 387-393.

Longo F.J. (1972) The effects of cytochalasin B on the events of fertilization in the surf clam, Spisula solidissima. I. Polar body formation. Journal of Experimental Zoology 182, 321-344.

Longo F.J., Mathews L. \& Hedgecock D. (1993) Morphogenesis of maternal and paternal genomes in fertilized oyster eggs, Crassostres gigas T. Effects of cytochalasin B at different periods during meiotic maturation. Biological Bulletin 185, 197-214.

Lu J.K. (1986) The combined effects of salinity and temperature on meiosis and early mitosis of the Pacific oyster, Crassostrea gigas T., oocytes. M.Sc. Thesis, University of Washington, Seattle, WA.

Quillet E. \& Panelay P.J. (1986) Triploidy induction by thermal shocks in the Pacific oyster, Crassostrea gigas T. Aquaculture 57, 271-279.

Stanley J.G., Allen S.K. \& Hidu H. (1981) Polyploidy induced in the Amencan oyster, Crassostrea virginica, with cytochalasin B. Aquaculture 23, 1-10.

Stanley J.G., Hidu H. \& Allen S.K. (1984) Growth of American oysters, Crassostrea virginica, increased by polyploidy induced by blocking meiosis I but not meiosis II. Aquaculture 37, 147-155.

Stephens L.B. (1989) Inhibition of the first polar body formation in Crassostrea gigas produces tetraploids, not meiotic I triploids. M.Sc. Thesis, University of Washington, Seattle, WA.

Strathmann M.F. (1987) Reproduction and Development of Marine Invertebrates of the Northern Pacific Coast. University of Washington Press, Seattle, WA.

Tabarini C.L. (1984) Induced triploidy in the bay scallop, Argopecten irradians, and its effect on growth and gametogenesis. Aquaculture 42, 151-160.

Thorgaard G.H. \& Gall G.A.E. (1979) Adult triploids in a rainbow trout, Salmo gairdneri, family. Genetics 93 , 961-973.

Yamamoto S.Y., Sugawara T.N. \& Oshino A. (1988) Induced triploidy in the Pacific oyster, Crassostrea gigas T., and performance of triploid larvae. Tohoku Journal of Agricultural Research 39, 47-59. 
This document is a scanned copy of a printed document. No warranty is given about the accuracy of the copy. Users should refer to the original published version of the material. 